\title{
Tunable High Refractive Index Polymer Hybrid and Polymer- Inorganic Nanocomposite Coatings
}

\author{
Angus W. Ritchie, Harrison J. Cox, Hassan I. Gonabadi, Steve J. Bull, and Jas Pal S. Badyal* \\ Cite This: ACS Appl. Mater. Interfaces 2021, 13, 33477-33484 \\ Read Online
}

ABSTRACT: Atomized spray plasma deposition (ASPD) provides a single-step, lowtemperature, and dry approach for the preparation of high refractive index hybrid polymer or polymer-inorganic nanocomposite coatings. Refractive indices as high as 1.936 at $635 \mathrm{~nm}$ wavelength have been obtained for ASPD 4-bromostyrene/toluene-

$\mathrm{TiO}_{2}$ nanocomposite layers containing low titania loadings. Thin films with any desired refractive index up to 1.936 can be easily deposited onto a variety of substrates by varying the precursor mixture composition. ASPD overcomes disadvantages commonly associated with alternative fabrication methods for depositing high refractive index coatings (elevated temperatures, wet processes, UV curing steps, and much greater inorganic loadings).

KEYWORDS: refractive index, hybrid polymer, polymer-inorganic, nanocomposite, atomized, plasma, coating

\section{INTRODUCTION}

High refractive index materials attract a great deal of interest because of their wide range of technological applications, including optical lenses, ${ }^{1}$ waveguides, ${ }^{2}$ antireflective coatings, ${ }^{3}$ and as encapsulants for both light-emitting diodes (LEDs) ${ }^{4}$ and photovoltaic cells. ${ }^{5}$ Given that inorganic materials have an inherently high refractive index $(n)$, one approach to achieve even higher refractive index coatings is through the use of pure inorganic thin films. Coatings of $\mathrm{ZnO}, \mathrm{ZrO}_{2}$, and $\mathrm{TiO}_{2}$ are reported to have refractive indices of $1.87,{ }^{6} 1.96,{ }^{7}$ and $2.28,{ }^{8}$ respectively. However, these coatings require multiple-step fabrication procedures and elevated temperatures and can be incompatible with common plastic substrates. Most common polymer materials have a refractive index between 1.3 and 1.7.' More recently, high refractive index polymers (HRIPs) with refractive indices as high as 1.85 have been reported. ${ }^{10-12}$ These HRIPs are prepared by introducing atoms or substituents of high molar refraction into the polymer chain. Such substituents include aromatic rings, ${ }^{13}$ halogens (except for fluorine), ${ }^{14}$ sulfur, ${ }^{15}$ phosphorus, ${ }^{16}$ and silicon. ${ }^{17}$ Although these materials offer the advantages of being lightweight and easy to process, their preparation also requires lengthy and costly synthetic procedures. ${ }^{18}$

Hybrid organic-inorganic composite materials potentially offer high refractive indices and can be prepared using a variety of different methods. The most common is the sol-gel method in which a metal alkoxide precursor is mixed with an organic compound followed by heating during which hydrolysis and condensation of the metal alkoxide leads to the formation of metal oxide domains within an organic matrix coating (refractive index values, $n=1.7-1.9) .{ }^{19-22}$ Sol-gel coatings containing $\mathrm{TiO}_{2}$ are reported with refractive index values of $n$ $=1.92-2.05$, but the inorganic loading is high (49-90 wt $\%) .^{23-25}$ Other types of high refractive index composite coatings contain inorganic materials such as $\mathrm{PbS}^{26} \mathrm{Si}^{27}$ and $\mathrm{V}_{2} \mathrm{O}_{5} ;{ }^{28}$ however, these require, for instance, the use of $\mathrm{H}_{2} \mathrm{~S}$ gas $^{26}$ or a complex milling process, ${ }^{27}$ and the coatings absorb strongly in the visible wavelength range. ${ }^{28}$ In all of these cases, the inorganic content also tends to be high (40-90 wt \%) and the synthesis can be lengthy involving wet processing and elevated temperatures.

An alternative approach for fabricating organic-inorganic composite coatings is dispersing inorganic nanoparticles into an organic polymer prior to application onto substrates. A key requirement of this method is the use of nanoparticles $(<25$ $\mathrm{nm}$ in size, which is well below one tenth of the wavelength of visible light) in order to avoid poor optical transparency due to Rayleigh scattering. ${ }^{29}$ As with sol-gel coatings, high refractive indices in the range of $1.7-1.972$ can be attained but again rely upon high levels of inorganic material loadings (45-97 wt $\%) .{ }^{30-32}$ Carbon black particles have been used at lower loadings (10 wt \%, $n=1.833)$; however, the coating transparency can be comprised as a consequence of agglomeration. $^{33}$ It is also possible to disperse inorganic nanoparticles into monomers prior to polymerization. ${ }^{34,35}$ Refractive indices as high as $n=1.972$ are reported for this approach at $50 \mathrm{wt} \%$ loading of graphene oxide. ${ }^{36}$ As with the sol-gel coatings, these nanoparticle/monomer dispersions and nanoparticle/polymer dispersions all require high temperatures $\left(120-300{ }^{\circ} \mathrm{C}\right)$ or additional UV curing steps. Therefore, a demand exists for ambient temperature, single-step fabrication

Received: April 21, 2021

Accepted: June 29, 2021

Published: July 13, 2021 
methods for high refractive index coatings containing low levels of inorganic materials.

Atomized spray plasma deposition (ASPD) is a scalable, single-step, room temperature, and dry method for the preparation of functional coatings. ${ }^{37-39}$ This encompasses the nebulization of liquid or slurry droplets into a nonequilibrium electrical discharge. At low energy inputs, high levels of structural retention (functionality) can be attained. In this article, high refractive index polymer coatings are prepared by ASPD using a 4-bromostyrene precursor $\left(n=1.595^{40}\right)$. The refractive index is further increased by mixing the 4bromostyrene precursor for ASPD with a higher refractive index solid (9-vinylcarbazole, $n=1.683^{41}$ ) or functionalized titania nanoparticles $\left(n_{\text {anatase }}=2.45 ; n_{\text {rutile }}=2.70^{20}\right)$, leading to the deposition of high refractive index hybrid polymer or polymer-titania nanocomposite coatings, respectively, Scheme 1.

\section{Scheme 1. Atomized Spray Plasma Deposition of 4- Bromostyrene-9-vinylcarbazole Hybrid and 4- Bromostyrene/Toluene $+\mathrm{TiO}_{2}$ Nanocomposite High Refractive Index Layers}

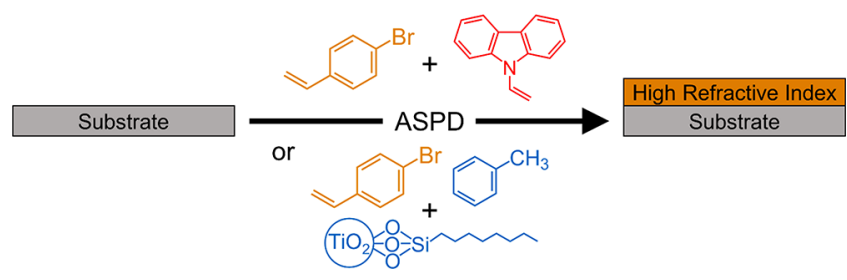

\section{EXPERIMENTAL SECTION}

2.1. Atomized Spray Plasma Deposition. Precursor materials used were 4-bromostyrene (+95\%, Apollo Scientific Ltd.), 9vinylcarbazole (98\%, Sigma-Aldrich Ltd.), and trimethoxyoctylsilane-functionalized titania nanoparticles $(21 \mathrm{~nm}$ average particle size, Aeroxide T805, Evonik Industries AG). For the case of the 4bromostyrene precursor mixed with trimethoxyoctylsilane-functionalized titania nanoparticles, 20 or $40 \% \mathrm{v} / \mathrm{v}$ of toluene (99.99 wt \%, Fisher Scientific Ltd.) was added to improve dispersion. ${ }^{42}$ Liquidsolid slurry monomer-nanoparticle mixtures were sonicated for 60 min to fully disperse the nanoparticles (Clifton ultrasonic bath, Nickel-Electro Ltd.) and then loaded into a sealable glass delivery tube. This precursor slurry mixture was then degassed using multiple freeze-pump-thaw cycles. Substrates used for coating were silicon (100) wafers $(0.014-0.024 \Omega \mathrm{cm}$ resistivity, Silicon Valley Microelectronics Inc.), quartz slides $(20 \mathrm{~mm} \times 10 \mathrm{~mm} \times 1 \mathrm{~mm}$, UQG Ltd.), and polyethylene terephthalate film (PET, capacitor grade, 0.10 $\mathrm{mm}$ thickness, Lawson Mardon Ltd.). These were cleaned by sonication in a $1: 1 \mathrm{v} / \mathrm{v}$ propan-2-ol (+99.5 wt \%, Fisher Scientific Ltd.)/cyclohexane (+99.5\%, Fisher Scientific Ltd.) solvent mixture, followed by UV-ozone treatment (model UV.TC.EU.003, BioForce Nanosciences Inc.), and a final sonication step in the propan-2-ol/ cyclohexane solvent mixture. After air drying, substrates were placed downstream in line-of-sight from the ASPD atomizer, Figure 1.

Atomized spray plasma deposition (ASPD) was carried out in an electrodeless, cylindrical, T-shape glass reactor (volume of $1195 \mathrm{~cm}^{3}$, base pressure of less than $3 \times 10^{-3} \mathrm{mbar}$, and a leak rate better than 2 $\times 10^{-9} \mathrm{~mol} \mathrm{~s}^{-1}$ ) enclosed in a Faraday cage. ${ }^{44}$ The chamber was pumped by a $30 \mathrm{~L} \mathrm{~min}^{-1}$ two-stage rotary pump (model E2M2, Edwards Vacuum Ltd.) attached to a liquid nitrogen cold trap, and the system pressure was monitored by a thermocouple gauge. An L$\mathrm{C}$ impedance matching network was used to minimize the standing wave ratio for power transmitted from a $13.56 \mathrm{MHz}$ radio frequency (RF) power supply to a copper coil $(4 \mathrm{~mm}$ diameter, 7 turns,

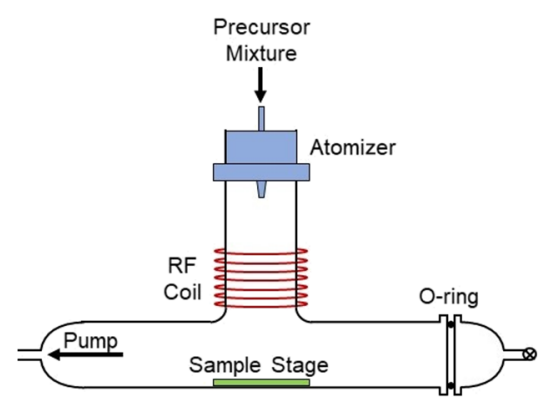

Figure 1. Atomized spray plasma deposition (ASPD) chamber. $^{37,43}$

spanning $5.5 \mathrm{~cm}$ ). The copper coil was located $12.5 \mathrm{~cm}$ downstream from the atomizer nozzle ( $18 \mu \mathrm{m}$ diameter median droplet size, model no. $8700-120$, Sono-Tek Corp. $\left.{ }^{45,46}\right)$, which was driven by a broadband ultrasonic generator $(120 \mathrm{kHz}$, model no. 06-05108, Sono-Tek Corp.). Prior to each coating deposition, the chamber was scrubbed with detergent, rinsed with propan-2-ol and acetone (+99\%, Fisher Scientific Ltd.), and oven dried. Next, continuous wave air plasma was ignited for $30 \mathrm{~min}$ at $0.2 \mathrm{mbar}$ pressure and $50 \mathrm{~W}$ power in order to remove any remaining trace contaminants from the chamber walls. Ambient temperature deposition was carried out using a $30 \mathrm{~W}$ continuous wave plasma in conjunction with atomization of the precursor into the reaction chamber employing an optimized flow rate of $15 \pm 1 \times 10^{-4} \mathrm{~mL} \mathrm{~s}^{-1}$. Upon plasma extinction, the atomizer was switched off and the system was evacuated to base pressure, followed by venting to atmosphere.

2.2. Refractive Index. The refractive indices and thicknesses of coated silicon wafer substrates were measured using a spectrophotometer (model nkd-6000, Aquila Instruments Ltd.). The obtained transmittance-reflectance curves (a 350-1000 nm wavelength range and a parallel $(p)$ polarized light source at a $30^{\circ}$ incident angle) were fitted to the Cauchy model for dielectric materials, using a modified Levenberg-Marquardt method (version 2.2 software, Pro-Optix, Aquila Instruments Ltd.). ${ }^{47,48}$

2.3. UV-Vis Transmittance Spectroscopy. UV-vis transmittance spectra of coated quartz slides were acquired in the 200$1000 \mathrm{~nm}$ wavelength range using a UV-vis-NIR spectrophotometer (model Cary 5000 UV-vis-NIR, Agilent Technologies Inc.).

2.4. Infrared Spectroscopy. Fourier transform infrared (FTIR) analysis was carried out using an FTIR spectrometer (model Spectrum One, Perkin Elmer Inc.) equipped with a liquid nitrogencooled mercury-cadmium-telluride (MCT) detector. The spectra were averaged over 100 scans at a resolution of $4 \mathrm{~cm}^{-1}$ across the $450-4000 \mathrm{~cm}^{-1}$ wavenumber range. Attenuated total reflection (ATR) spectra of 4-bromostyrene, 9-vinylcarbazole, toluene, and trimethoxyoctylsilane- $\mathrm{TiO}_{2}$ nanoparticles were obtained using a single-reflection diamond brazed into a tungsten carbide accessory (model Golden Gate, Specac Ltd.). Reflection-absorption infrared spectroscopy (RAIRS) of ASPD hybrid and nanocomposite layercoated silicon wafers was performed using a variable angle reflectionabsorption accessory (Specac Ltd.) fitted with a KRS-5 polarizer (to remove the s-polarized component) set at an angle of $55^{\circ}$ to the substrate normal (sampling depth of $0.5-20 \mu \mathrm{m}$ for RAIRS ${ }^{49}$ ).

2.5. Scanning Electron Microscopy. ASPD-coated silicon wafer substrates were mounted onto carbon disks supported on aluminum stubs and then coated with a thin evaporated gold layer $(5-10 \mathrm{~nm}$, Polaron SEM Coating Unit, Quorum Technologies Ltd.). Electron micrographs were acquired using a scanning electron microscope (model Vega 3LMU, Tescan Orsay Holdings a.s.) operating in a secondary electron detection mode, in conjunction with an $8 \mathrm{kV}$ accelerating voltage, and a working distance of $12-15 \mathrm{~mm}$. SEM cross-section analysis was performed to cross-check the film thicknesses measured using the spectrophotometer, Supporting Information (Tables S1 and S2). For SEM cross-section analysis, coated silicon wafer substrates were frozen in liquid nitrogen, fractured, and then mounted onto carbon disks supported on $45^{\circ}$ tilt aluminum stubs. 
2.6. Hardness. Hardness and contact modulus measurements were made at a $200 \mathrm{~nm}$ depth for ASPD coatings deposited onto silicon wafers using a Hysitron Triboindenter fitted with a general purpose Berkovich diamond tip (tip end radius of $500 \mathrm{~nm}$ ). Tests were performed under load control to reduce time-dependent deformation effects and were analyzed by the method of Oliver and Pharr. ${ }^{50}$ Twenty-five indentations were made on each coating at a range of loads from 0.1 to $2 \mathrm{mN}$ giving contact depths from 100 to $900 \mathrm{~nm}$. There was some variation of mechanical properties with contact depth, which is due to a combination of time-dependent deformation (which mainly affects hardness) and the presence of the substrate (which mainly affects contact modulus). It is often suggested that the hardness of a coating independent of the substrate can be assessed if the contact depth is less than $10 \%$ of the coating thickness and that the elastic modulus of the substrate will contribute to the measurement at a much lower percentage; ${ }^{51}$ the results are reported at a fixed contact depth of $200 \mathrm{~nm}$ to minimize this effect.

\section{RESULTS}

3.1. Coating Deposition. Photographs of the 4bromostyrene and 4-bromostyrene/toluene $+8 \% \mathrm{TiO}_{2}$ ASPD coatings deposited onto silicon wafer, quartz window, and PET polymer film substrates illustrate the substrateindependent nature of the ASPD technique, Supporting Information (Figure S1). Hardness and contact modulus values were measured to be $1.06 \pm 0.16$ and $40.6 \pm 19.9 \mathrm{GPa}$, respectively, for the 4-bromostyrene ASPD coatings and 0.59 \pm 0.18 and $23.0 \pm 13.5 \mathrm{GPa}$, respectively, for the 4bromostyrene/toluene $+8 \% \mathrm{TiO}_{2}$ ASPD coatings. Scanning electron microscopy images of the ASPD layers showed that the 4-bromostyrene and $3: 2 \mathrm{v} / \mathrm{v}$ 4-bromostyrene/toluene surfaces were relatively smooth in appearance, Supporting Information (Figure S2). The incorporation of 9-vinylcarbazole or titania particles into the respective coatings slightly increased the coating surface roughness, with the submicrometer features for the latter case being attributed to the incorporated $\mathrm{TiO}_{2}$ nanoparticles, Supporting Information (Figure S2). Spectrophotometry and scanning electron microscopy thickness measurements showed that the atomized spray plasma deposition (ASPD) coatings were uniform in thickness, Supporting Information (Tables S1 and S2). For the 4-bromostyrene precursor, the optimal ASPD film growth rate $\left(325 \pm 63 \mathrm{~nm} \mathrm{~min}{ }^{-1}\right)$ was measured to be an order of magnitude greater than that reported for the conventional vapor phase plasma deposition of styrene $\left(10-20 \mathrm{~nm} \mathrm{~min}^{-1}\right)^{52}$ and can be attributed to the higher precursor flow rate associated with the atomization of liquid droplets during ASPD. ${ }^{37}$

3.2. Refractive Index. The refractive index of the ASPD 4bromostyrene layer $\left(n_{635 \mathrm{~nm}}=1.569 \pm 0.005\right)$ was found to be comparable to the literature value for the 4-bromostyrene precursor $\left(n_{589.3 \mathrm{~nm}}=1.595^{40}\right)$, Figure 2 . Incorporation of the high refractive index solid compound 9-vinylcarbazole $\left(n_{\text {poly }(\text { vinylcarbazole })}=1.683^{41}\right)$ into the ASPD 4-bromostyrene layer led to an enhancement in the optical properties yielding refractive indices as high as $n_{635 \mathrm{~nm}}=1.648 \pm 0.008$ for a loading of $50 \% \mathrm{w} / \mathrm{v} 9$-vinylcarbazole, Figure 2. This improvement in refractive index was across the entire measured wavelength range. For 9-vinylcarbazole concentrations exceeding $50 \% \mathrm{w} / \mathrm{v}$, the precursor mixture became too viscous to sustain homogeneous atomization. The observed rise in the refractive index value with increasing 9-vinylcarbazole content demonstrates how the optical properties of the ASPD 4bromostyrene coatings can be easily tuned in order to achieve
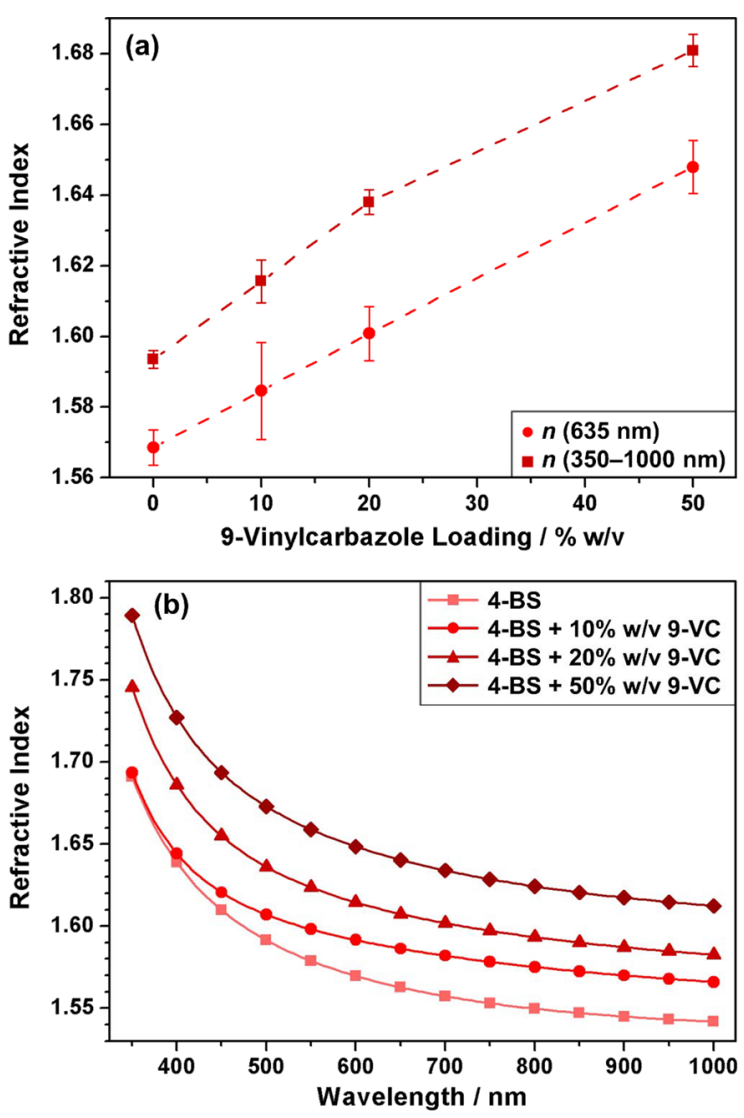

Figure 2. (a) Refractive index at $635 \mathrm{~nm}$ and averaged over a 350$1000 \mathrm{~nm}$ wavelength range for ASPD 4-bromostyrene-9-vinylcarbazole hybrid layers as a function of 9-vinylcarbazole concentration in the precursor mixture and (b) refractive index variation of ASPD 4bromostyrene layer and ASPD 4-bromostyrene-9-vinylcarbazole hybrid layers across the $350-1000 \mathrm{~nm}$ wavelength range (lines represent different precursor compositions; actual measurements were made every $5 \mathrm{~nm}$ between 350 and $1000 \mathrm{~nm}$ - a symbol plotted every $50 \mathrm{~nm}$ is used to differentiate between the lines). 4-Bromostyrene and 9 -vinylcarbazole have been abbreviated to 4-BS and 9-VC, respectively.

a desired refractive index by simply varying the 9-vinylcarbazole loading in the precursor mixture.

An even greater enhancement in refractive index values was achieved for the case of ASPD 4-bromostyrene-titania nanocomposite layers, Figure 3. This entailed the addition of some toluene to the 4-bromostyrene carrier in order to help disperse the hydrophobic trimethoxyoctylsilane- $\mathrm{TiO}_{2}$ nanoparticles within the precursor mixture. In the absence of nanoparticles, the ASPD 4-bromostyrene/toluene (4:1 v/v) layer displayed a slightly lower refractive index $\left(n_{635 \mathrm{~nm}}=1.555\right.$ $\pm 0.015)$ compared to the pure 4-bromostyrene coating $\left(n_{635 \mathrm{~nm}}=1.569 \pm 0.005\right)$, which is expected due to the addition of a lower refractive index liquid into the precursor mixture $\left(n_{632.8 \mathrm{~nm} \text { (toluene) }}=1.4939\right) .{ }^{53}$ Incorporation of trimethoxyoctylsilane- $\mathrm{TiO}_{2}$ nanoparticles into this host 4bromostyrene/toluene layer led to a significant increase in refractive index yielding values as high as $n_{635 \mathrm{~nm}}=1.796 \pm$ 0.034 for a precursor slurry loading of $5 \% \mathrm{w} / \mathrm{v}$ titania nanoparticles dispersed in a 4:1 v/v 4-bromostyrene/toluene mixture, Figure 3. The refractive index of these ASPD 4bromostyrene/toluene + titania nanocomposite layers is greatly enhanced across the entire measured wavelength 

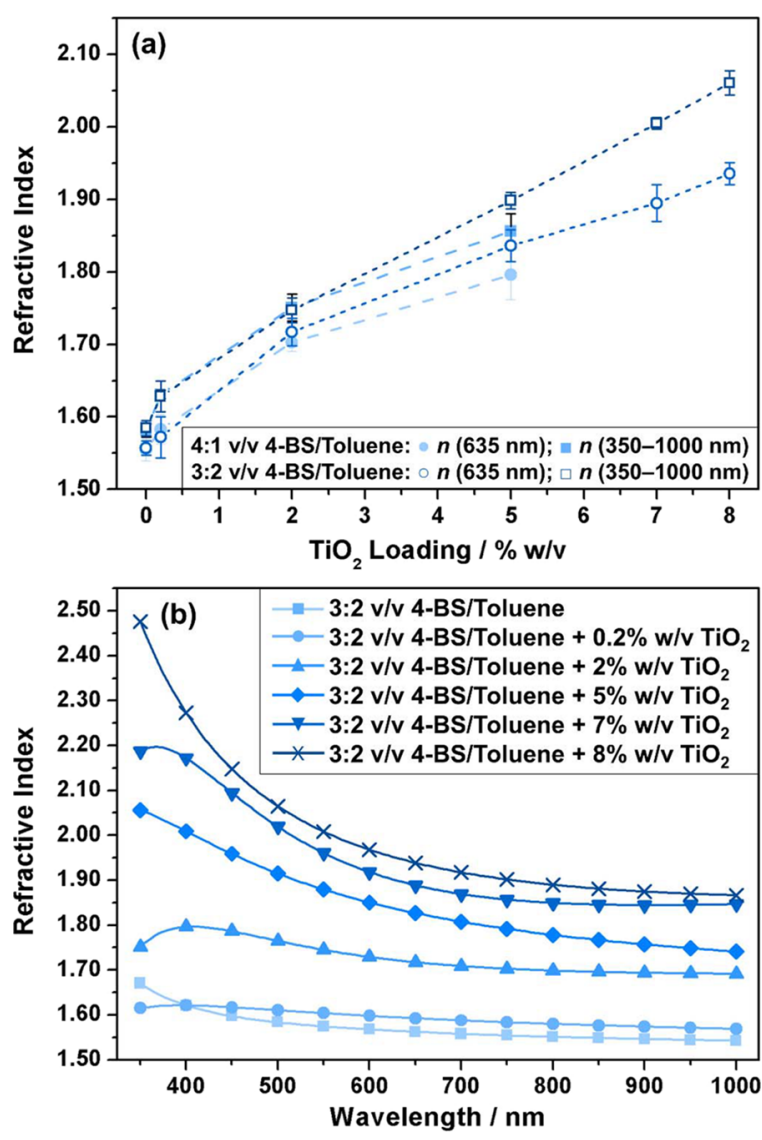

Figure 3. (a) Refractive index at $635 \mathrm{~nm}$ and averaged over the 350$1000 \mathrm{~nm}$ wavelength range for ASPD 4-bromostyrene/toluene + titania nanocomposite layers as a function of trimethoxyoctylsilanefunctionalized titania loading concentration and (b) refractive index variation of the ASPD 3:2 v/v 4-bromostyrene/toluene layer and ASPD 3:2 v/v 4-bromostyrene/toluene $+x \% \mathrm{w} / \mathrm{v}$ trimethoxyoctylsilane- $\mathrm{TiO}_{2}$ nanocomposite layers across the $350-1000 \mathrm{~nm}$ wavelength range (lines represent different precursor compositions; actual measurements were made every $5 \mathrm{~nm}$ between 350 and $1000 \mathrm{~nm}$, a symbol plotted every $50 \mathrm{~nm}$ is used to differentiate between the lines). 4-Bromostyrene has been abbreviated to 4-BS.

range $(350-1000 \mathrm{~nm})$. The slight drop in refractive index toward lower wavelengths has also been previously observed for other systems, for example, wet-coated polymer-titania composite films, where it is attributed to the incident photon frequency becoming approximately equal to the plasma frequency leading to anomalous dispersion. ${ }^{54}$ For a fixed nanoparticle loading, the refractive index could be increased further by raising the toluene content $\left(n_{635 \mathrm{~nm}}=1.836 \pm 0.022\right.$ for $5 \% \mathrm{w} / \mathrm{v}$ titania nanoparticles dispersed in a $3: 2 \mathrm{v} / \mathrm{v} 4-$ bromostyrene/toluene mixture) - this can be attributed to a better dispersion of nanoparticles in the precursor mixture by using larger amounts of toluene. Control experiments with the titania loading kept constant at $5 \% \mathrm{w} / \mathrm{v}$ while lowering the 4bromostyrene/toluene ratio further did not lead to any additional improvement in the refractive index beyond this optimal 3:2 v/v value (for instance, $5 \% \mathrm{w} / \mathrm{v} \mathrm{TiO}_{2}$ nanoparticles in a $2: 3 \mathrm{v} / \mathrm{v}$ 4-bromostyrene/toluene mixture gave $n_{635} \mathrm{~nm}=$ $1.819 \pm 0.015)$. Using this optimal $3: 2 \mathrm{v} / \mathrm{v}$ ratio of 4bromostyrene/toluene, the $\mathrm{TiO}_{2}$ nanoparticle loading could be extended to beyond $5 \% \mathrm{w} / \mathrm{v}$. A precursor slurry loading of $8 \%$ $\mathrm{w} / \mathrm{v}$ titania gave refractive indices as high as $n_{635 \mathrm{~nm}}=1.936 \pm$ 0.015 , Figure 3. For $\mathrm{TiO}_{2}$ nanoparticle concentrations exceeding $8 \% \mathrm{w} / \mathrm{v}$ nanoparticle loading, the precursor mixture became too viscous to sustain homogeneous atomization. This significant enhancement in refractive index values attained by incorporating trimethoxyoctylsilane- $\mathrm{TiO}_{2}$ nanoparticles at still relatively low concentrations further demonstrates the capability to fine tune the nanocomposite layer optical properties.

3.3. UV-Vis Transmittance Spectroscopy. UV-vis transmittance spectra of the ASPD 3:2 v/v 4-bromostyrene/ toluene layers show that the coatings exhibit good transparency in the 450-1000 $\mathrm{nm}$ wavelength range, Figure 4. Upon

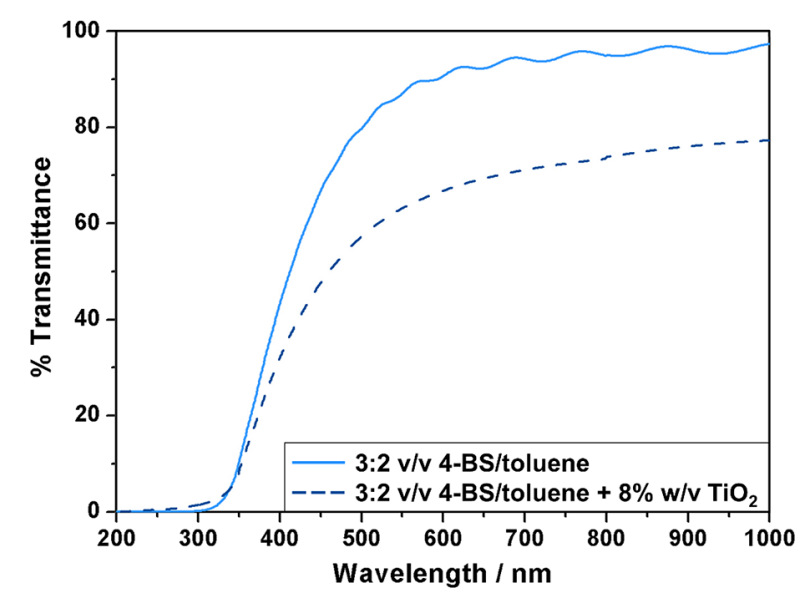

Figure 4. UV-vis transmittance spectra for ASPD 3:2 v/v 4bromostyrene/toluene layer (solid line) and ASPD 3:2 v/v 4bromostyrene/toluene $+8 \% \mathrm{w} / \mathrm{v} \mathrm{TiO}_{2}$ nanocomposite layer (dashed line). 4-Bromostyrene has been abbreviated to 4-BS.

incorporation of $8 \% \mathrm{w} / \mathrm{v}$ trimethoxyoctylsilane- $\mathrm{TiO}_{2}$ nanoparticles, the UV-vis transmittance dropped but still exceeded $50 \%$ between 450 and $1000 \mathrm{~nm}$. This drop in optical transmittance is most likely due to scattering of the light by the $\mathrm{TiO}_{2}$ nanoparticles. ${ }^{55}$

3.4. Infrared Spectroscopy. Infrared spectroscopy showed high levels of structural retention for the ASPD poly(4-bromostyrene) layers, Figure 5. Characteristic poly(4bromostyrene) ring absorbances include aromatic $\mathrm{C}-\mathrm{H}$ stretching $\left(3031 \mathrm{~cm}^{-1}\right.$ and $\left.3060 \mathrm{~cm}^{-1}\right)$, para-substituted benzene ring $\mathrm{C}=\mathrm{C}$ stretching $\left(1488 \mathrm{~cm}^{-1}\right.$ and $\left.1590 \mathrm{~cm}^{-1}\right)$, and aromatic $\mathrm{C}-\mathrm{Br}$ (para) stretching $\left(1073 \mathrm{~cm}^{-1}\right){ }^{56,57}$ Disappearance of the peaks due to the vinyl $\mathrm{C}=\mathrm{C}$ bond associated with the precursor molecule confirms polymerization via the 4-bromostyrene vinyl group during ASPD: = $\mathrm{CH}_{2}$ wagging $\left(908 \mathrm{~cm}^{-1}\right),=\mathrm{CH}_{2}$ twisting $\left(986 \mathrm{~cm}^{-1}\right)$, and $\mathrm{C}=\mathrm{C}$ stretching $\left(1629 \mathrm{~cm}^{-1}\right) .55,58$

The infrared spectrum of the ASPD 4-bromostyrene-50\% w/v 9-vinylcarbazole layer clearly shows incorporation of 9vinylcarbazole into the hybrid polymer layer due to the appearance of an absorption band at $1333 \mathrm{~cm}^{-1}$ associated with $\mathrm{C}-\mathrm{N}$ stretching, Figure $5 .{ }^{59}$ A characteristic orthosubstituted benzene ring absorbance is also now observed at $1452 \mathrm{~cm}^{-1}$ attributed to the extended 9-vinylcarbazole aromatic structure. ${ }^{60}$ As with the ASPD 4-bromostyrene layer, disappearance of the absorbances associated with the vinyl $\mathrm{C}=\mathrm{C}$ bond present in the 9 -vinylcarbazole precursor is consistent with conventional polymerization taking place at the vinyl $\mathrm{C}=\mathrm{C}$ double bond: $=\mathrm{CH}_{2}$ wagging $\left(854 \mathrm{~cm}^{-1}\right),=\mathrm{CH}_{2}$ twisting $\left(960 \mathrm{~cm}^{-1}\right)$, and $\mathrm{C}=\mathrm{C}$ stretching $\left(1636 \mathrm{~cm}^{-1}\right) .{ }^{56,58}$ 


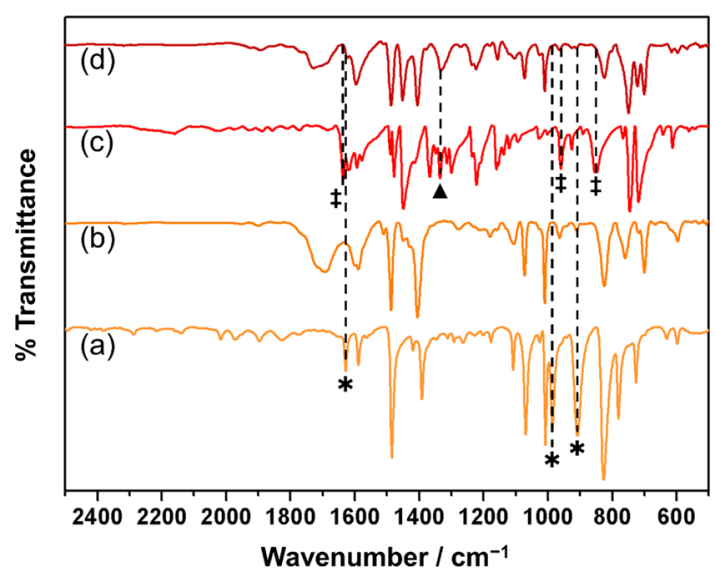

Figure 5. Infrared spectra: (a) the ATR 4-bromostyrene liquid precursor, (b) RAIRS ASPD 4-bromostyrene layer, (c) ATR 9vinylcarbazole solid precursor, and (d) the RAIRS ASPD 4bromostyrene-9-vinylcarbazole hybrid polymer layer $(50 \% \mathrm{w} / \mathrm{v} 9$ vinylcarbazole). The asterisk $(*)$ and double dagger $(\$)$ denote absorbances associated with the polymerizable vinyl $\mathrm{C}=\mathrm{C}$ double bond contained in the 4-bromostyrene and 9-vinylcarbazole precursors, respectively. A triangle $(\boldsymbol{\Delta})$ denotes $\mathrm{C}-\mathrm{N}$ stretching absorbance at $1333 \mathrm{~cm}^{-1}$. Infrared spectra across the $500-4000 \mathrm{~cm}^{-1}$ range are given in the Supporting Information, Figure S3. Assignments are given in the Supporting Information, Table S3.

For the ASPD 4-bromostyrene/toluene + titania nanocomposite layers, $\mathrm{TiO}_{2}$ nanoparticle incorporation throughout the bulk of the layers is evident from the broad absorption band at around $643 \mathrm{~cm}^{-1}$ associated with $\mathrm{Ti}-\mathrm{O}-\mathrm{Ti}$ stretching, ${ }^{61}$ Figure 6 . Aliphatic $\mathrm{C}-\mathrm{H}$ stretching absorbances at 2868 and $2929 \mathrm{~cm}^{-1}$ are indicative of some toluene molecule-plasma reactions, Supporting Information (Figure S4). ${ }^{55}$ This incorporation of toluene into the nanocomposite structure also shifts the characteristic para-substituted benzene

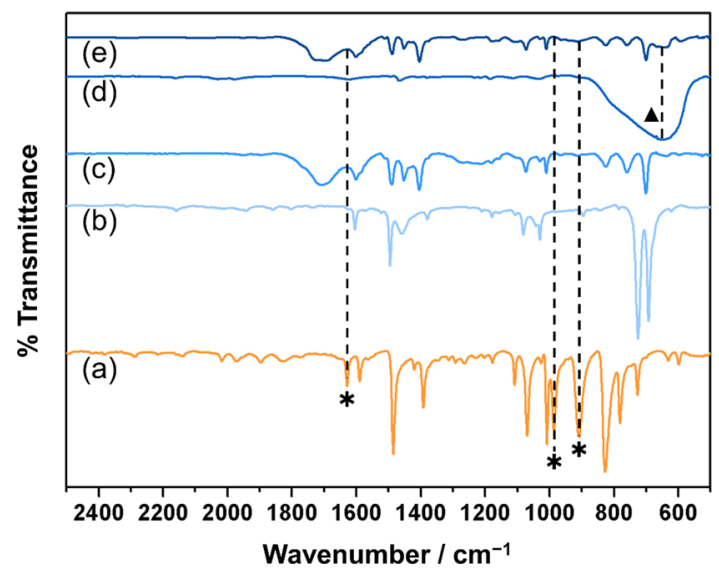

Figure 6. Infrared spectra: (a) ATR 4-bromostyrene liquid precursor, (b) ATR toluene liquid precursor, (c) RAIRS ASPD 3:2 v/v 4bromostyrene/toluene layer, (d) ATR trimethoxyoctylsilane- $\mathrm{TiO}_{2}$ nanoparticles, and (e) RAIRS ASPD 3:2 v/v 4-bromostyrene/toluene $+8 \% \mathrm{w} / \mathrm{v}$ trimethoxyoctylsilane- $\mathrm{TiO}_{2}$ nanocomposite layer. An asterisk $(*)$ denotes absorbances associated with the polymerizable vinyl $\mathrm{C}=\mathrm{C}$ double bond contained in the 4-bromostyrene precursor. A triangle $(\boldsymbol{\Delta})$ denotes $\mathrm{Ti}-\mathrm{O}-\mathrm{Ti}$ stretching absorbance at $643 \mathrm{~cm}^{-1}$. Infrared spectra the across $500-4000 \mathrm{~cm}^{-1}$ range are given in the Supporting Information, Figure S4. Assignments are given in the Supporting Information, Table S4. ring $\mathrm{C}=\mathrm{C}$ stretching absorbances of 4-bromostyrene toward higher wavenumbers (1489 and $1601 \mathrm{~cm}^{-1}$ ), which is consistent with forming a mixture of para- (para $\mathrm{C}=\mathrm{C}$ stretching of 4-bromostyrene precursor: 1485 and $1589 \mathrm{~cm}^{-1}$ ) and mono- (mono $\mathrm{C}=\mathrm{C}$ stretching of toluene precursor: 1495 and $\left.1604 \mathrm{~cm}^{-1}\right)$ substituted benzene rings. ${ }^{56}$

\section{DISCUSSION}

Refractive index is a measure of how fast light travels through a material relative to the speed of light in a vacuum. When light passes through the boundary between two different materials, it changes direction (refraction) due to a change in speed caused by a disruption of electron density at the interface. As a consequence, materials with high polarizability have a high refractive index. Molar refractivity is a measure of the polarizability of a material. For a polymer, the refractive index is dependent upon the molar refractions and molar volumes of both the polymer backbone and the functional groups present. ${ }^{55}$ It can be predicted by summing the molar refractions of all the polymer substituents, and therefore high refractive index polymers contain substituents with a high molar refraction. ${ }^{2}$ Aromatic rings and halogen atoms (except for fluorine) have a high molar refraction due to their large polarizability and high electron density. ${ }^{10}$ Hence, incorporation of these groups into a polymeric coating is an effective way for enhancing its index of refraction. This accounts for the high refractive index value measured for the ASPD 4-bromostyrene layer $\left(n_{635 \mathrm{~nm}}=1.569 \pm 0.005\right.$ compared to $n_{589.3 \mathrm{~nm}}=1.595$ for the 4-bromostyrene precursor ${ }^{40}$ ), Figure 2 . Infrared spectroscopy of this layer confirms the presence of aromatic groups (aromatic $\mathrm{C}-\mathrm{H}$ and $\mathrm{C}=\mathrm{C}$ stretches) and bromine atoms (aromatic $\mathrm{C}-\mathrm{Br}$ stretch), Figure 5.

Further enhancement in refractive index has been achieved through the mixing of the highly aromatic molecule 9vinylcarbazole with the 4-bromostyrene precursor reaching refractive indices as high as $n_{635 \mathrm{~nm}}=1.648 \pm 0.008$ for a loading of $50 \% \mathrm{w} / \mathrm{v} 9$-vinylcarbazole, Figure 2 . An increase in refractive index is measured across the entire wavelength range due to the incorporation of additional aromatic groups $\left(n_{\text {poly }(\text { vinylcarbazole })}=1.683^{41}\right)$. The observed enhancement in refractive index $(\Delta n=+0.079)$ at maximum 9-vinylcarbazole loading $(50 \% \mathrm{w} / \mathrm{v})$ is in line with previous reports that utilize 9 -vinylcarbazole to increase refractive index $(n)$ using a blade coating $^{63}$ or moulding process ${ }^{64}$ followed by UV polymerization. Overall, greater refractive indices are achieved in the present study by utilizing a higher refractive index host polymer. Furthermore, syntheses of these earlier reported polymer systems required multiple additives (a cross-linking agent, UV starter to initiate polymerization, and a stabilizer) and UV irradiation and high-temperature baking steps, none of which are required for the single-step ASPD process.

Higher refractive indices are reported previously by incorporating titania into composite coatings using the solgel method ${ }^{19-25}$ or by nanoparticle dispersion into polymers $^{30-32}$ and monomer mixtures. ${ }^{35}$ These rely upon the inherently high refractive index of titania $(n=2.45$ for anatase; $n=2.70$ for rutile). ${ }^{20}$ This approach has been extended in the present study by dispersing low loadings of trimethoxyoctylsilane-functionalized titania nanoparticles (consisting of a mixture of anatase and rutile ${ }^{65}$ ) into the 4-bromostyrene precursor for ASPD leading to values as high as $n_{635 \mathrm{~nm}}=1.796$ \pm 0.034 for a precursor slurry loading of $5 \% \mathrm{w} / \mathrm{v}$ titania nanoparticles dispersed in a $4: 1 \mathrm{v} / \mathrm{v}$ 4-bromostyrene/toluene 
mixture, Figure 3. Alkyl group surface functionalization of the $\mathrm{TiO}_{2}$ nanoparticles helps dispersion in the 4-bromostyrene precursor. ${ }^{55}$ Toluene addition to the precursor mixture further assists dispersion of the alkyl group-functionalized titania nanoparticles. ${ }^{42}$ The refractive index obtained for the $3: 2 \mathrm{v} / \mathrm{v}$ 4-bromostyrene/toluene $+8 \% \mathrm{w} / \mathrm{v}$ titania ASPD nanocomposite coating $\left(n_{635 \mathrm{~nm}}=1.936\right)$ exceeds a previous report where titania was added prior to UV-induced liquid-phase monomer polymerization $\left(n=1.861^{35}\right)$. The refractive index reported here is also higher than for other nanocomposite coatings where nanoparticles were incorporated into a host polymer containing bromine atoms and aromatic rings in order to obtain high refractive index films. ${ }^{66,67}$ Furthermore, the refractive index attained in the current investigation is larger than earlier values for low loading of polymer-inorganic nanocomposite coatings ( $\leq 10 \mathrm{wt} \%$ inorganic material): $n=$ $1.73\left(8\right.$ wt $\left.\% \mathrm{TiO}_{2}\right),{ }^{54} n=1.81\left(8\right.$ wt $\left.\% \mathrm{HfO}_{2}\right),{ }^{68}$ and $n=$ 1.833 (10 wt \% carbon black). ${ }^{33}$ Synthesis of coatings containing titania where the refractive index was slightly higher than the 1.936 value reported in the present study includes wet preparation by nanoparticle dispersion into polymers $^{32}$ and the sol-gel method. ${ }^{23-25,54}$ However, in all of these cases, the titania loading was greater (16-93.4 wt \%) than that of employed here, which often results in higher optical loss and reduces the processability of the organic matrix. ${ }^{34}$ Additionally, these methods involve complex synthetic procedures, long processing times, wet steps, high temperatures, and post-deposition curing steps. In contrast, ASPD is a straightforward single-step, dry, low-temperature technique and therefore provides a much simpler approach to depositing high refractive index polymer-titania nanocomposite coatings. It also offers potential for the fabrication of lowrefractive index polymer-based coatings through the incorporation of low-refractive index additives. ${ }^{69,70}$ Furthermore, in contrast to conventional spin-coating processes, which require multiple deposition cycles to build up the layer thickness, the ASPD method allows continuous thickness control combined with fast deposition rates.

\section{CONCLUSIONS}

High refractive index hybrid polymer and polymer-titania nanocomposite coatings have been prepared in a single step using atomized spray plasma deposition (ASPD). The fabricated polymer-inorganic nanocomposite coatings have very high refractive indices at low titania loadings compared to previously reported polymer-titania coatings (which typically have loadings $>30 \mathrm{wt} \%$ ). This single-step approach offers a dry, low-temperature method for conformably coating any substrate with a high refractive index coating or a coating with a desired refractive index. The simplicity of this approach makes it a promising route for depositing thin films for optical applications.

\section{ASSOCIATED CONTENT}

\section{SI Supporting Information}

The Supporting Information is available free of charge at https://pubs.acs.org/doi/10.1021/acsami.1c07372.

Photographs, scanning electron microscopy images, infrared spectra, refractive indices, and coating thicknesses (PDF)

\section{AUTHOR INFORMATION}

\section{Corresponding Author}

Jas Pal S. Badyal - Department of Chemistry, Durham

University, Durham DH1 3LE, England, U.K.; 다. orcid.org/

0000-0002-5086-5737; Email: j.p.badyal@durham.ac.uk

\section{Authors}

Angus W. Ritchie - Department of Chemistry, Durham University, Durham DH1 3LE, England, U.K.

Harrison J. Cox - Department of Chemistry, Durham University, Durham DH1 3LE, England, U.K.; 이이.org/ 0000-0001-5966-6083

Hassan I. Gonabadi - School of Engineering, Newcastle University, Newcastle-upon-Tyne NE1 7RU, England, U.K.

Steve J. Bull - School of Engineering, Newcastle University, Newcastle-upon-Tyne NE1 7RU, England, U.K.

Complete contact information is available at:

https://pubs.acs.org/10.1021/acsami.1c07372

\section{Author Contributions}

J.P.S.B. and A.W.R. devised the approach for high refractive index coatings. A.W.R. performed atomized spray plasma deposition and characterization studies. H.J.C. acquired infrared spectra. H.I.G. and S.J.B. undertook coating hardness testing. The manuscript was jointly drafted by J.P.S.B. and A.W.R. All authors gave the final approval for publication.

\section{Funding}

A.W.R. was funded by the Engineering and Physical Sciences Research Council (EPSRC, PhD studentship reference EP/ M507854/1). H.J.C. was supported by the British Council (Katip Çelebi - Newton Fund grant reference 333595).

\section{Notes}

The authors declare no competing financial interest.

Data created during this research can be accessed at https:// collections.durham.ac.uk

\section{ACKNOWLEDGMENTS}

We thank T. Davey of the Electron Microscopy Research Services at Newcastle University for assistance with SEM analysis.

\section{REFERENCES}

(1) Matsuda, T.; Funae, Y.; Yoshida, M.; Yamamoto, T.; Takaya, T. Optical Material of High Refractive Index Resin Composed of SulfurContaining Aromatic Methacrylates. J. Appl. Polym. Sci. 2000, 76, 5054.

(2) Zevin, M.; Reisfeld, R. Preparation and Properties of Active Waveguides Based on Zirconia Glasses. Opt. Mater. 1997, 8, 37-41.

(3) Krogman, K. C.; Druffel, T.; Sunkara, M. K. Anti-Reflective Optical Coatings Incorporating Nanoparticles. Nanotechnology 2005, 16, S338-S343.

(4) Kim, J.-S.; Yang, S.-C.; Bae, B.-S. Thermally Stable Transparent Sol-Gel Based Siloxane Hybrid Material with High Refractive Index for Light Emitting Diode (LED) Encapsulation. Chem. Mater. 2010, 22, 3549-3555.

(5) Ma, M.; Mont, F. W.; Poxson, D. J.; Cho, J.; Schubert, E. F.; Welser, R. E.; Sood, A. K. Enhancement of Photovoltaic Cell Response due to High-Refractive-Index Encapsulants. J. Appl. Phys. 2010, 108, No. 043102.

(6) Zhao, D.; Mourey, D. A.; Jackson, T. N. Low-Temperature Pulsed-PECVD ZnO Thin-Film Transistors. J. Electron. Mater. 2010, 39, 554-558. 
(7) Ehrhart, G.; Capoen, B.; Robbe, O.; Boy, P.; Turrell, S.; Bouazaoui, M. Structural and Optical Properties of $n$-Propoxide SolGel Derived $\mathrm{ZrO}_{2}$ Thin Films. Thin Solid Films 2006, 496, 227-233.

(8) Antonello, A.; Guglielmi, M.; Bello, V.; Mattei, G.; Chiasera, A.; Ferrari, M.; Martucci, A. Titanate Nanosheets as High Refractive Layer in Vertical Microcavity Incorporating Semiconductor Quantum Dots. J. Phys. Chem. C 2010, 114, 18423-18428.

(9) Liu, J.-G.; Ueda, M. High Refractive Index Polymers: Fundamental Research and Practical Applications. J. Mater. Chem. 2009, 19, 8907-8919.

(10) Macdonald, E. K.; Shaver, M. P. Intrinsic High Refractive Index Polymers. Polym. Int. 2015, 64, 6-14.

(11) Higashihara, T.; Ueda, M. Recent Progress in High Refractive Index Polymers. Macromolecules 2015, 48, 1915-1929.

(12) Griebel, J. J.; Namnabat, S.; Kim, E. T.; Himmelhuber, R.; Moronta, D. H.; Chung, W. J.; Simmonds, A. G.; Kim, K.-J.; van der Laan, J.; Nguyen, N. A.; Dereniak, E. L.; Mackay, M. E.; Char, K.; Glass, R. S.; Norwood, R. A.; Pyun, J. New Infrared Transmitting Material via Inverse Vulcanization of Elemental Sulfur to Prepare High Refractive Index Polymers. Adv. Mater. 2014, 26, 3014-3018.

(13) Wen, P.; He, R.; Li, X.-D.; Lee, M.-H. Syntheses and Characterizations of High Refractive Index and Low Birefringence Polyimides Containing Spirobifluorene in the Side Chain. Polymer 2017, 117, 76-83.

(14) Minns, R. A.; Gaudiana, R. A. Design and Synthesis of High Refractive Index Polymers. II. J. Macromol. Sci., Part A 1992, 29, 1930.

(15) You, N.-H.; Suzuki, Y.; Yorifuji, D.; Ando, S.; Ueda, M. Synthesis of High Refractive Index Polyimides Derived from 1,6$\operatorname{Bis}(p$-aminophenylsulfanyl)-3,4,8,9-tetrahydro-2,5,7,10-tetrathiaanthracene and Aromatic Dianhydrides. Macromolecules 2008, 41, 6361-6366.

(16) Olshavsky, M.; Allcock, H. R. Polyphosphazenes with High Refractive Indices: Optical Dispersion and Molar Refractivity. Macromolecules 1997, 30, 4179-4183.

(17) Bhagat, S. D.; Chatterjee, J.; Chen, B.; Stiegman, A. E. High Refractive Index Polymers Based on Thiol-Ene Cross-Linking Using Polarizable Inorganic/Organic Monomers. Macromolecules 2012, 45, 1174-1181.

(18) Olshavsky, M. A.; Allcock, H. R. Polyphosphazenes with High Refractive Indices: Synthesis, Characterization, and Optical Properties. Macromolecules 1995, 28, 6188-6197.

(19) Ho, W. F.; Uddin, M. A.; Chan, H. P. The Stability of High Refractive Index Polymer Materials for High-Density Planar Optical Circuits. Polym. Degrad. Stab. 2009, 94, 158-161.

(20) Yuwono, A. H.; Liu, B.; Xue, J.; Wang, J.; Elim, H. I.; Ji, W.; Li, Y.; White, T. J. Controlling the Crystallinity and Nonlinear Optical Properties of Transparent $\mathrm{TiO}_{2}-\mathrm{PMMA}$ Nanohybrids. J. Mater. Chem. 2004, 14, 2978-2987.

(21) Lee, L.-H.; Chen, W.-C. High-Refractive-Index Thin Films Prepared from Trialkoxysilane-Capped Poly(methyl methacrylate)Titania Materials. Chem. Mater. 2001, 13, 1137-1142.

(22) Flaim, T. D.; Wang, Y.; Mercado, R. High-Refractive-Index Polymer Coatings for Optoelectronics Applications. Adv. Opt. Thin Films 2004, 5250, 423-434.

(23) Rao, Y.; Chen, S. Molecular Composites Comprising $\mathrm{TiO}_{2}$ and Their Optical Properties. Macromolecules 2008, 41, 4838-4844.

(24) Liou, G.-S.; Lin, P.-H.; Yen, H.-J.; Yu, Y.-Y.; Tsai, T.-W.; Chen, W.-C. Highly Flexible and Optical Transparent 6F-PI/TiO ${ }_{2}$ Optical Hybrid Films with Tunable Refractive Index and Excellent Thermal Stability. J. Mater. Chem. 2010, 20, 531-536.

(25) Himmelhuber, R.; Gangopadhyay, P.; Norwood, R. A.; Loy, D. A.; Peyghambarian, N. Titanium Oxide Sol-Gel Films with Tunable Refractive Index. Opt. Mater. Express 2011, 1, 252-258.

(26) Zimmennann, L.; Weibel, M.; Caseri, W.; Suter, U. W. High Refractive Index Films of Polymer Nanocomposites. J. Mater. Res. 1993, 8, 1742-1748.
(27) Papadimitrakopoulos, F.; Wisniecki, P.; Bhagwagar, D. E. Mechanically Attrited Silicon for High Refractive Index Nanocomposites. Chem. Mater. 1997, 9, 2928-2933.

(28) Oubaha, M.; Elmaghrum, S.; Copperwhite, R.; Corcoran, B.; McDonagh, C.; Gorin, A. Optical Properties of High Refractive Index Thin Films Processed at Low Temperature. Opt. Mater. 2012, 34, 1366-1370.

(29) Althues, H.; Henle, J.; Kaskel, S. Functional Inorganic Nanofillers for Transparent Polymers. Chem. Soc. Rev. 2007, 36, 1454-1465.

(30) Elim, H. I.; Cai, B.; Kurata, Y.; Sugihara, O.; Kaino, T.; Adschiri, T.; Chu, A.-L.; Kambe, N. Refractive Index Control and Rayleigh Scattering Properties of Transparent $\mathrm{TiO}_{2}$ Nanohybrid Polymer. J. Phys. Chem. B 2009, 113, 10143-10148.

(31) Kurata, Y.; Sugihara, O.; Kaino, T.; Komatsu, K.; Kambe, N. Thermo-Optic Controllable Hybrid Photonic Polymers Containing Inorganic Nanoparticles. J. Opt. Soc. Am. B 2009, 26, 2377-2381.

(32) Liu, B.-T.; Tang, S.-J.; Yu, Y.-Y.; Lin, S.-H. High-RefractiveIndex Polymer/Inorganic Hybrid Films Containing High $\mathrm{TiO}_{2}$ Contents. Colloids Surf., A 2011, 377, 138-143.

(33) Xue, P.; Wang, J.; Bao, Y.; Li, Q.; Wu, C. Synergistic Effect Between Carbon Black Nanoparticles and Polyimide on Refractive Indices of Polyimide/Carbon Black Nanocomposites. New J. Chem. 2012, 36, 903-910.

(34) Luo, K.; Zhou, S.; Wu, L. High Refractive Index and Good Mechanical Property UV-Cured Hybrid Films Containing Zirconia Nanoparticles. Thin Solid Films 2009, 517, 5974-5980.

(35) Rao, Y.; Antalek, B.; Minter, J.; Mourey, T.; Blanton, T.; Slater, G.; Slater, L.; Fornalik, J. Organic Solvent-Dispersed $\mathrm{TiO}_{2}$ Nanoparticle Characterization. Langmuir 2009, 25, 12713-12720.

(36) Zhang, G.; Zhang, H.; Zhang, X.; Zhu, S.; Zhang, L.; Meng, Q.; Wang, M.; Li, Y.; Yang, B. Embedding Graphene Nanoparticles into Poly $(N, N$ '-dimethylacrylamine) to Prepare Transparent Nanocomposite Films with High Refractive Index. J. Mater. Chem. 2012, 22, 21218-21224.

(37) Wood, T. J.; Ward, L. J.; Badyal, J. P. S. Super-Adhesive Polymer-Silica Nanocomposite Layers. ACS Appl. Mater. Interfaces 2013, 5, 9678-9683.

(38) Ward, L. J.; Schofield, W. C. E.; Badyal, J. P. S.; Goodwin, A. J.; Merlin, P. J. Atmospheric Pressure Plasma Deposition of Structurally Well-Defined Polyacrylic Acid Films. Chem. Mater. 2003, 15, 14661469.

(39) Goodwin, A. J.; Leadley, S. R.; O’Neill, L.; Duffield, P. J.; McKechnie, M. T.; Pugh, S. Coating Compositions. Patent US 20080118734A1, May 22, 2008.

(40) Walling, C.; Briggs, E. R.; Wolfstirn, K. B.; Mayo, F. R. Copolymerization. X. The Effect of Meta- and Para-Substitution on the Reactivity of the Styrene Double Bond. J. Am. Chem. Soc. 1948, $70,1537-1542$.

(41) van Krevelen, D. W.; te Nijenhuis, K. Properties of Polymers; $4^{\text {th }}$ Ed.; Elsevier B. V.: Amsterdam, The Netherlands, 2009; p 923.

(42) Iijima, M.; Kobayakawa, M.; Kamiya, H. Tuning the Stability of $\mathrm{TiO}_{2}$ Nanoparticles in Various Solvents by Mixed Silane Alkoxides. J. Colloid Interface Sci. 2009, 337, 61-65.

(43) Castaneda-Montes, I.; Ritchie, A. W.; Badyal, J. P. S. Atomised Spray Plasma Deposition of Hierarchical Superhydrophobic Nanocomposite Surfaces. Colloids Surf., A 2018, 558, 192-199.

(44) Ehrlich, C. D.; Basford, J. A. Recommended Practices for the Calibration and Use of Leaks. J. Vac. Sci. Technol., A 1992, 10, 1-17.

(45) Berger, H. L.; Mowbray, D. F.; Copeman, R. A.; Russell, R. J. Ultrasonic Atomizing Nozzle and Method U.S. Patent US 7712680B2, May 11, 2010.

(46) Sono-Tek Innovation by Design: What Makes Ultrasonic Nozzles Unique? https://www.sono-tek.com/ultrasonic-coating/howultrasonic-nozzles-work/ (Accessed 13 June 2021).

(47) Diebold, A. C.; Chism, W. W. Characterisation and Metrology of Medium Dielectric Constant Gate Dielectric Films. In High Dielectric Constant Materials: VSLI MOSFET Applications; Huff, H. R.; Gilmer, D. C. Eds.; Springer-Verlag: Berlin, 2005; p 486. 
(48) Lovering, D. NKD-6000 Technical Manual; Aquila Instruments: Cambridge, U.K., 1999.

(49) Chakrabarti, C. L.; Akh, G.; Hutton, J. C. ATR and Reflectance IR Spectroscopy, Applications. Spectrochim. Acta, Part B 1999, 33, 153-193.

(50) Oliver, W. C.; Pharr, G. M. An Improved Technique for Determining Hardness and Elastic Modulus Using Load and Displacement Sensing Indentation Experiments. J. Mater. Res. 1992, $74,1564-1580$

(51) Chen, J.; Bull, S. J. On the Factors Affecting the Critical Indenter Penetration for Measurement of Coating Hardness. Vacuum 2009, 83, 911-920.

(52) Fahmy, A.; Mix, R.; Schönhals, A.; Friedrich, J. Structure of Plasma-Deposited Copolymer Films Prepared from Acrylic Acid and Styrene: Part 1 Dependence on the Duty Cycle. Plasma Processes Polym. 2012, 9, 273-284.

(53) Beysens, D.; Calmettes, P. Temperature Dependence of the Refractive Indices of Liquids: Deviation from the Lorentz-Lorentz Formula. J. Chem. Phys. 1977, 66, 766-771.

(54) Alsaad, A.; Al Dairy, A. R.; Ahmad, A.; Qattan, I. A.; Al Fawares, S.; Al-Bataineh, Q. Synthesis and Characterization of Polymeric (PMMA-PVA) Hybrid Thin Films Doped with $\mathrm{TiO}_{2}$ Nanoparticles Using Dip-Coating Technique. Crystals 2021, 11, 99.

(55) Lü, C.; Yang, B. High Refractive Index Organic-Inorganic Nanocomposites: Design, Synthesis and Application. J. Mater. Chem. 2009, 19, 2884-2901.

(56) Lin-Vien, D.; Colthup, N. B.; Fateley, W. G.; Grasselli, J. G. The Handbook of Infrared and Raman Characteristic Frequencies of Organic Molecules; Academic Press, Inc.: San Diego, 1991.

(57) Katritzky, A. R.; Lagowski, J. M. 489. Infrared Absorption of Substituents in Aromatic Systems. Part V. Halogeno-compounds. J. Chem. Soc. 1960, 2421-2422.

(58) Wood, T. J.; Brown, P. S.; Badyal, J. P. S. Atomized Spray Plasma Deposition of Structurally Well-Defined Bioactive Coatings. Plasma Chem. Plasma Process. 2014, 34, 1019-1031.

(59) Li, Y.; Yang, J.; Xu, J. In Situ IR Spectroscopic Study of Poly $(N$ vinylcarbazole) Film During Electrochemical Doping. J. Appl. Polym. Sci. 1996, 61, 2085-2089.

(60) Reyna-González, J. M.; Aguilar-Martínez, M.; BautistaMartínez, J. A.; Rivera, E.; González, I.; Roquero, P. Influence of the Acidity Level on the Electropolymerization of $N$-vinylcarbazole: Electrochemical Study and Characterization of Poly(3,6- $\mathrm{N}$-vinylcarbazole). Polymer 2006, 47, 6664-6672.

(61) Pirson, A.; Mohsine, A.; Marchot, P.; Michaux, B.; Van Cantfort, O.; Pirard, J. P.; Lecloux, A. J. Synthesis of $\mathrm{SiO}_{2}-\mathrm{TiO}_{2}$ Xerogels by Sol-Gel Process. J. Sol-Gel Sci. Technol. 1995, 4, 179-185.

(62) Yang, C.-J.; Jenekhe, S. A. Group Contribution to Molar Refraction and Refractive Index of Conjugated Polymers. Chem. Mater. 1995, 7, 1276-1285.

(63) Eiselt, T.; Preinfalk, J.; Gleißner, U.; Lemmer, U.; Hanemann, T. Development and Characterization of Adjustable Refractive Index Scattering Epoxy Acrylate Polymer Layers. In Light Manipulating Organic Materials and Devices III; International Society for Optics and Photonics: 2016; 99390Q.

(64) Gleißner, U.; Bonaus, S.; Megnin, C.; Hanemann, T. Refractive Index Increase of Acrylate-Based Polymers by Adding Soluble Aromatic Guest-Molecules. Polym. Adv. Technol. 2017, 28, 506-510.

(65) Suh, Y. J.; Cho, K. Immobilization of Nanoscale Sunscreening Agents onto Natural Halloysite Micropowder. Mater. Trans. 2015, 56, 899-904.

(66) Yao, B.; Hu, X.; Liu, J.; Chen, K.; Liu, J. Preparation and Properties of High Refractive Index $\mathrm{ZrO}_{2}$ Nano-Hybrid Materials. Mater. Lett. 2020, 261, 126878.

(67) Hu, X.; Yao, B.; Liu, J.; Liu, J.; Chen, K.; Yan, M.; Wang, L. Preparation and Properties of High Refractive Index UV-Cured Titanium Hybrid Optical Materials. Mater. Lett. 2020, 265, 127466.

(68) Bae, W. J.; Trikeriotis, M.; Sha, J.; Schwartz, E. L.; Rodriguez, R.; Zimmerman, P.; Giannelis, E. P.; Ober, C. K. High Refractive
Index and High Transparency $\mathrm{HfO}_{2}$ Nanocomposites for Next Generation Lithography. J. Mater. Chem. 2010, 20, 5186-5189.

(69) Noack, J.; Fritz, C.; Flügel, C.; Hemmann, F.; Gläsel, H.-J.; Kahle, O.; Dreyer, C.; Bauer, M.; Kemnitz, E. Metal Fluoride-Based Transparent Nanocomposites with Low Refractive Indices. Dalton Trans. 2013, 42, 5706-5710.

(70) Cai, S.; Zhang, Y.; Zhang, H.; Yan, H.; Lv, H.; Jiang, B. Sol-Gel Preparation of Hydrophobic Silica Antireflective Coatings with Low Refractive Index by Base/Acid Two-Step Catalysis. ACS Appl. Mater. Interfaces 2014, 6, 11470-11475. 